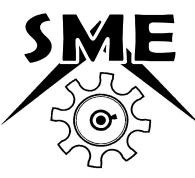

ESTD 2005

\title{
PERFORMANCE ANALYSIS OF PLATE HEAT EXCHANGER WITH NANOFLUID USING MILK PASTEURIZATION PROCESS
}

\author{
Mohamed Thoufick K \\ Department of Mechanical Engineering, Arifa Institute of Technology, Esanoor, Tamil Nadu-610204, India
}

\begin{abstract}
Experimentally to analyzed the enhance performance of Plate heat exchanger in milk pasteurization process using nanofluid at different concentration of $0.1 \%, 0.15 \%, 0.2 \% 0.25 \%$ and $0.3 \%$. in this work the nanoparticles like $\mathrm{Al}_{2} \mathrm{O}_{3}$ and the base fluid like dematerialized water is used to prepare nanofluid by using two steps method. Exchanger is one of the thermal energy transferring devices, which transfer the heat between different fluids. This is widely used in different application because of its compact in size and higher efficiency compared to other type of heat exchanger. The main focus of using nanofluid is that it has improvement in thermal conductivity. Then the hot fluid as milk and cold fluid as nanofluids are used. The heat transfer rate is increased with increasing the concentration of nanofluid. It conducted by varying operating parameters like mass flow rate of hot milk, mass flow rate of nanofluid, inlet and outlet temperatures of hot milk and inlet outlet temperature of nanofluid. The main objective of this work is to find out mass flow rate and overall, all heat transfer coefficient.
\end{abstract}

Keywords: Gasket Plate Heat Exchanger, $\mathrm{Al}_{2} \mathrm{O}_{3}$ Nanofluid and Heat Transfer Coefficient.

\section{Introduction}

Generally, A heat exchanger is a system used to transfer heat between two or more fluids. Heat exchangers are used in both cooling and heating processes. The fluids may be separated by a solid wall to prevent mixing or they may be in direct contact. They are widely used in space heating, refrigeration, air conditioning, power stations, chemical plants, petrochemical plants, petroleum refineries, natural-gas processing, and sewage treatment. The classic example of a heat exchanger is found in an internal combustion engine in which a circulating fluid known as engine coolant flows through radiator coils and air flows past the coils, which cools the coolant and heats the incoming air. Another example is the heat sink, which is a passive heat exchanger that transfers the heat generated by an electronic or a mechanical device to a fluid medium, often air or a liquid coolant. Shell and tube heat exchangers consist of a series of tubes which contain fluid that must be either heated or cooled. A second fluid runs over the tubes that are being heated or cooled so that it can either provide the heat or absorb the heat required. A set of tubes is called the tube bundle and can be made up of several types of tubes: plain, longitudinally finned, etc. Plate heat exchangers are typically used for high-pressure applications (with pressures greater than 30 bar and temperatures greater than $260^{\circ} \mathrm{C}$ ). This is because the plate heat exchangers are robust due to their shape. Many industrial plants will use plate heat exchangers for things such as pasteurization and waste heat recovery. For example, a manufacturing plant may use water to cool down a hot, newly manufactured beverage product. The hot finished liquid product needs to be cooled down before bottling so it passes through a plate heat exchanger which is connected to the cooling circuit of a chiller. This extracts the unwanted heat without the two fluids mixing.

The heat exchangers are classified as direct contact heat exchanger, indirect contact heat exchanger, surface heat exchanger, regenerative heat exchanger, parallel flow heat exchanger, counter flow heat exchanger, plate heat exchanger, and shell and tube heat exchanger. Bani kananeh et al. [1] have proposed that Fouling inside gasketed plate heat exchangers used in milk production has been reduced using nanocomposites coatings. The coated plates showed reduced deposit build up in comparison with the uncoated stainless steel. Marzia Giribaldi et al. [2] have proposed that a new small-scale continuous-flow HighTemperature Short-Time (HTST) pasteurizer has been designed for treating human milk. Helena F et.al. [3] have proposed that the continuous thermal processing of liquid foods with a three-section plate heat exchanger

*Corresponding Author - E- mail: salimmalick20@gmail.com 
(PHE), heat integration and a non-isothermal holding tube was modelled in order to derive the temperature history of the product and the lethality distribution. In order to validate and test the model, it was used to simulate the operation of a laboratory-scale plate pasteurizer processing an enzymic time-temperature integrator (TTI) at four temperature conditions $(70,75$, 80 and $85{ }^{\circ} \mathrm{C}$ ). Previous studies of residence time distribution and heat transfer in the equipment provided important parameters for the simulation.

Phavanee Narataruksa et al. [3] have proposed that Fouling by coconut milk at different heating temperatures. The results illustrated that the fouling factor increased, when the temperature fell due to a combination of chemical reaction fouling from proteins and precipitation fouling from fat. The fouling factor also increased, when the flow was lowered due to a slow rate of deposit removal introduced by small shear force. Combination of the two effects revealed that the effect of flow was less significant at higher temperatures. All results can be confirmed by an analysis of fouling compositions. At high temperature conditions, more denaturation of proteins resulted in less ability to entrap fat globules onto heating surface. Augustin et al. [4] have proposed that heat transfer fouling experiments were carried out in a temperature controlled stirred vessel using aqueous solutions of whey protein concentrate in the concentration range of 3 to $3.5 \mathrm{wt}-\%$ at a bulk temperature of $50{ }^{\circ} \mathrm{C}$ and $\mathrm{pH}$ of 6 . Heat transfer data were obtained from thermocouples embedded in an immersed electrical heating rod with various metal plates attached with-and-without surface treatments. K.S. Hong et al. [5] have proposed that Nanofluids have been attractive for the last few years with the enormous potential to improve the efficiency of heat transfer fluids. This work focuses on the effect of the clustering of nanoparticles on the thermal conductivity of nanofluids. Large enhancement of the thermal conductivity is observed in Fe nanofluids sonicated with high powered pulses.

\section{Plate Heat Exchanger}

The plate heat exchanger normally consists of corrugated plates assembled into a frame. The hot fluid flows in one direction in alternating chambers while the cold fluid flows in true counter-current flow in the other alternating chambers. The fluids are directed into their proper chambers either by a suitable gasket or a weld depending on the type of exchanger chosen. Traditionally, plate and frame exchangers have been used almost exclusively for liquid to liquid heat transfer. The best example is in the dairy industry. The corrugated pattern on the thermal plate induces a highly turbulent fluid flow. The high turbulence in the PHE leads to an enhanced heat transfer, to a low fouling rate, and to a reduced heat transfer area. Therefore, PHEs can be used as alternatives to shell-and-tube heat exchangers. R410A approximates an azeotropic behavior since it can be regarded as a pure substance because of the negligible temperature gliding.

The resulting flow passages are narrow, highly interrupted, and tortuous, and enhance the heat transfer rate and decrease fouling resistance by increasing the shear stress, producing secondary flow, and increasing the level of turbulence. The corrugations also improve the rigidity of the plates and form the desired plate spacing. Plates are designated as hard or soft, depending on whether they generate a high or low intensity of turbulence. Sealing between the two fluids is accomplished by elastomeric molded gaskets [typically, $5 \mathrm{~mm}(0.2$ inch $)$ thick] that are fitted in peripheral grooves. Gaskets are designed such that they compress about $25 \%$ of thickness in a bolted plate exchanger to provide a leak tight joint without distorting the thin plates. In the past, the gaskets were cemented in the grooves, but now, Snap-On gaskets, which do not require cementing, are common. The specification of plate heat exchanger is presented in Table 1.

Table 1. Specification of Plate Heat Exchanger

\begin{tabular}{clc}
\hline S.No. & \multicolumn{1}{c}{ Particulars } & Type/ Value \\
\hline 1. & Plate type & VT04 PHK \\
2. & $\begin{array}{l}\text { Heat Transfer Area (Total/ } \\
\text { unit) }\end{array}$ & $0.17 \mathrm{~m}^{2}$ \\
& $\begin{array}{l}\text { Number of plates (Total per } \\
\text { 3. }\end{array}$ & 9 \\
4. & unit) plate & $35.99 \mathrm{~K}$ \\
5. & Plate Material & AISI316 \\
6. & Gasket Material/ Gasket & NBR / Glued \\
& Type & $2 \times 4$ \\
7. & Internal flow (passes $\times$ & channels) \\
8. & No. of Frames & 1 \\
9. & Frame Material & CS-IS 2062 Gr B \\
10. & Surface & Painted RAL50 \\
\hline
\end{tabular}

\section{Nanofluid}

Nanofluid a fluid containing nanometer sized particles called nanoparticles. These fluids are colloidal suspension of nanoparticles with sized typically of the order 1-100 nm in base fluid. Modern nanotechnology provides great opportunities to process and produces materials with average crystallite size below $50 \mathrm{~nm}$.recognizing an opportunity to apply this emerging nanotechnology to established thermal energy engineering it was proposed by choi in 1993 that 
nanometer sized metallic particles could suspended in industrial heat transfer fluid such as water, ethylene glycol or engine oil to produce a new class of engineered fluids with thermal conductivity. The average size of particles used in nanofluids is below $50 \mathrm{~nm}$.

\section{Preparation of Nano Fluids}

In this study, PHE-water nanofluid was prepared by two-step method consisting of dispersion of nano particles purchased from Neutrino Co. in distilled water as the base fluid. In this nano particles with $5-15 \mathrm{~nm}$ in diameter and $20 \mathrm{~mm}$ in length were smoothly added to distilled water for about 3 minutes, which was on the magnet stirrer, and was continuously stirred for 45 minutes. Then, the suspension was subjected in an ultrasonic at for about 60 minutes its maintained at $90^{\circ} \mathrm{C}$ and a mechanical high-speed agitator was used in it to have a more stable nanofluid. The amount of surfactant was 2.5 times of weight of the nano particles. The volume of the nanofluids, for having an economic consumption of nano particles, investigations were chosen in weight fraction concentration instead of the volume fractions So, the nanofluids with $0.1 \%, 0.15 \%, 0.20 \%, 0.25 \%$ and $0.30 \%$ weight fractions were obtained by the method illustrated above. No sedimentation was observed after 2 days and even at low flow rates in the experiments. Also, to prevent from possible sedimentation, a new nanofluid was prepared and immediately used for each test.

\section{Experimental Investigation}

A scheme of the experimental setup is shown in Fig. 1. It mainly included two flow loops for hot and cold fluids is shows Hot flow loop consisted of an isothermal water bath (for milk as hot fluid) with a heater by $1500 \mathrm{~W}$ power and 5 Lit capacity, a centrifugal pump, a dampener (to minimize the vibration), and PHE as the test section of this process. The counter current heat exchange was established between hot and cold streams. The inlet and outlet temperatures of the nanofluid and milk were measured by four PT-100 thermocouples, which had precision of $0.1^{\circ} \mathrm{C}$ and were calibrated using a mercury thermometer at high and low temperatures of fluid. Water bath was set at the required temperature. After temperature of the nanofluid went up and exceeded the temperature, the pump was turned on, and the nanofluid was circulated. Since the hot fluid came back to the bath after passing through the PHE, its temperature suddenly fell down and then went up again to reach the set temperature. Before returning to the reservoir, flow rate of the nanofluid was measured from the time required capacity and a valve on the bottom. In the second loop, milk was pumped from the milk reservoir and, after warming in PHE, the pasteurized milk with higher temperature entered a cooler to keep constant temperature at the inlet of PHE by tap nanofluid as coolant. Thermocouples and flow rate measurements were the same at the nanofluid loop as described. In order to minimize the heat loss around the PHE, it was isolated by a glass wool. Bypass lines for both of the milk reservoir and water bath were used to control flow rates of the fluids The system needed 10 minutes to reach the steady-state condition, and then the temperatures were recorded. In this PHE, critical Reynolds number was 100 , and the experiments were carried out in both ranges of laminar and turbulent flow regimes for the nanofluid and just in the laminar flow for milk stream.

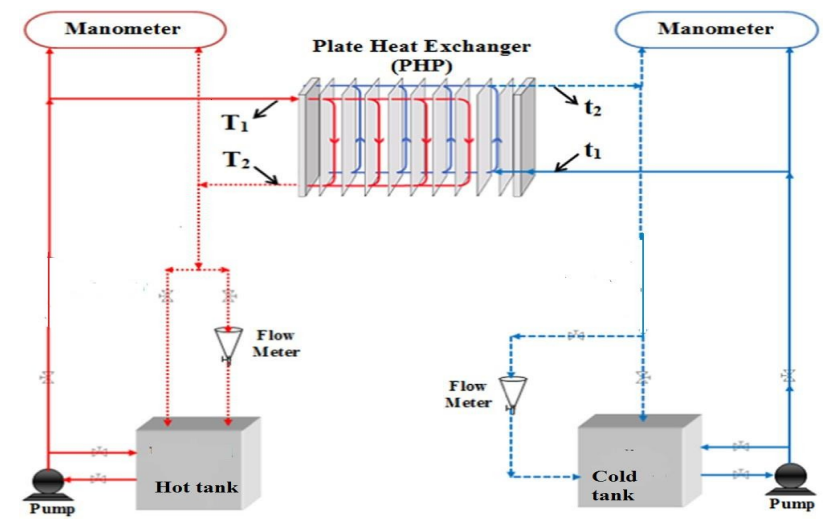

Fig. 1 Experimental Setup of Plate Heat Exchanger

\section{Data Analysis}

Experimental data have been used to calculate the heat transfer rate and over all heat transfer coefficient characteristics, each of the involved fluids using the equations (1), (2) and (3)

Specific Heat, $\mathrm{Cpnf}=\Phi C \mathrm{pp}+(1-\Phi) \mathrm{Cpf}$

Over All Heat Transfer Co-Efficient, $\mathrm{U}=[1 / \mathrm{hi}+1 / \mathrm{ho}]-1$

Heat Transfer Rate, $\mathrm{Q}=\mathrm{UA}(\Delta \mathrm{T}) \mathrm{m}$

\section{Results and Discussion}

In nanofluid-milk heat transfer various results are plotted based on different parameters such as heat transfer rate, specific heat, thermal conductivity, heat 
transfer coefficient. Fig. 2 shows the difference of concentration with respect specific heat. It is observing that concentration will increases with decrease the specific heat.

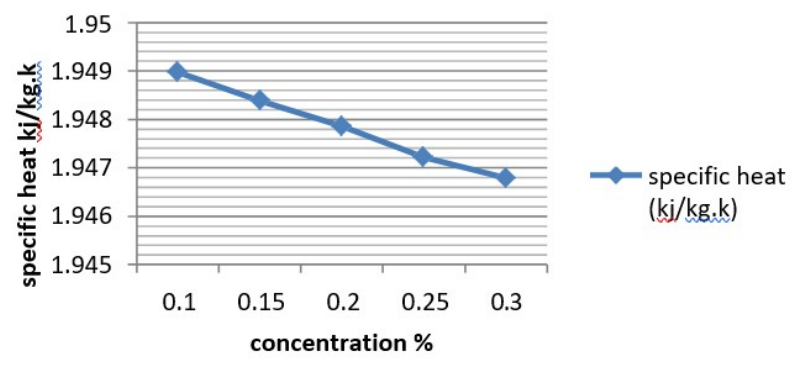

\section{Fig. 2 Concentration Vs Specific heat}

Fig. 3 shows the difference of concentration with respect thermal conductivity. Increase in concentration results into increase in thermal conductivity of fluid.

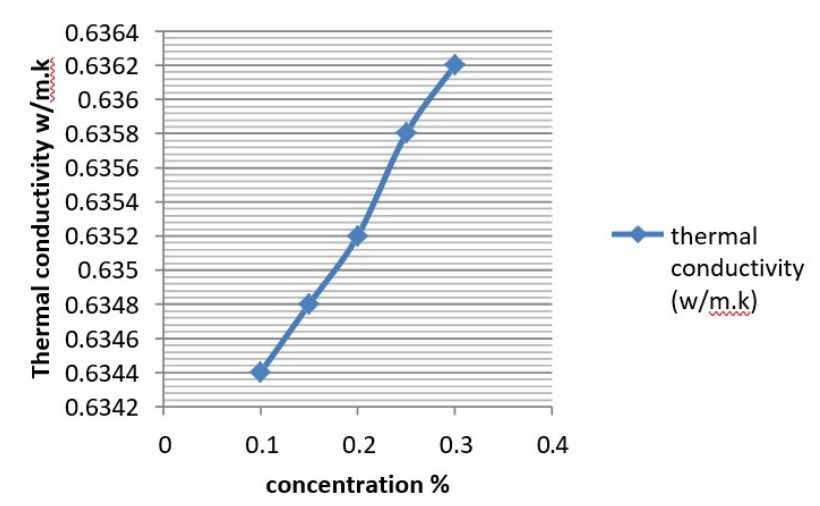

\section{Fig. 3 Concentration Vs Thermal conductivity}

Fig. 4 shows the difference of concentration with respect heat transfer rate. Increase in concentration results into increase in heat transfer rate of fluid.

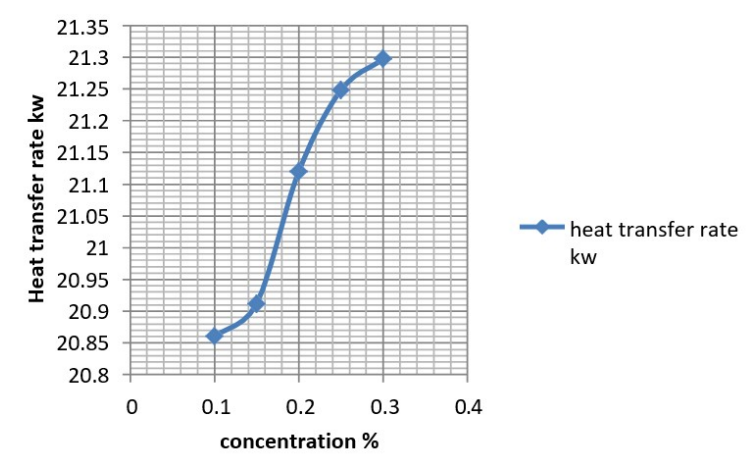

Figure 4. Concentration Vs Heat transfer rate
Fig. 5 shows the difference of concentration with respect overall heat transfer coefficient. Increase in concentration results into increase in overall heat transfer rate of fluid.

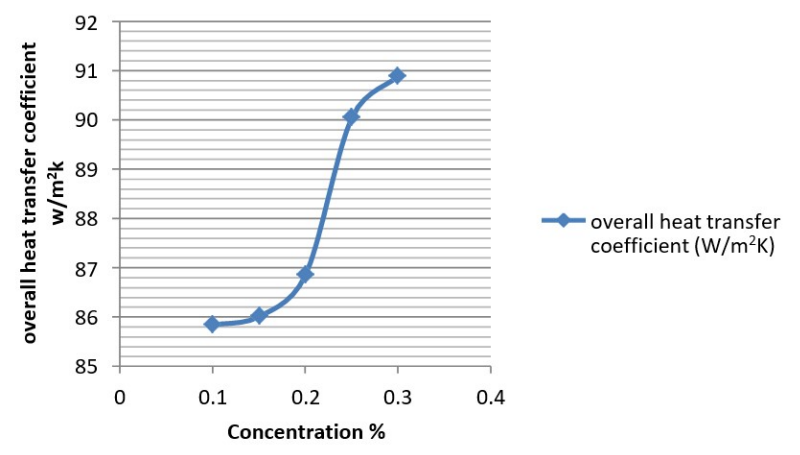

\section{Fig. 5 Concentration Vs overall heat transfer coefficient}

For the nano fluid-based heat transfer different results are based on different parameters such as heat transfer rate, over all heat transfer coefficient, mass flow rate, specific rate, thermal conductivity. Figure 6 show with the concentration with specific heat, thermal conductivity, heat transfer rate, overall heat transfer coefficient while increase the concentration the performance will be increased.

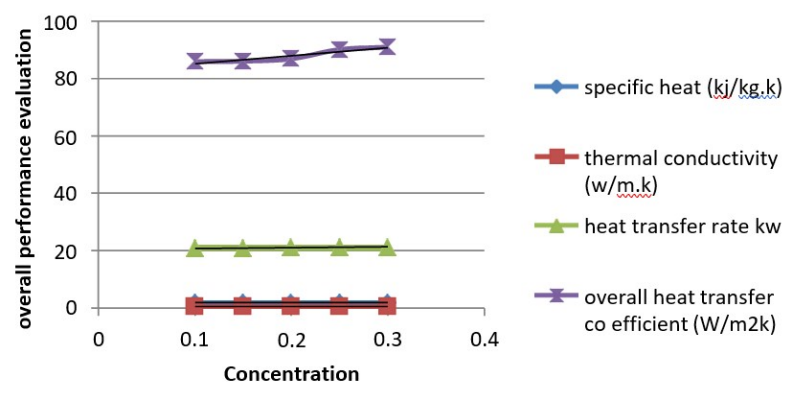

Fig. 6 Overall performance evaluation Vs concentration

\section{Conclusion}

This research work is focused on heat transfer analysis of corrugated PHE and also to investigate experimentally the performance of corrugated PHE with regard to convective specific heat, thermal conductivity, heat transfer coefficient, heat exchanger effectiveness and the following performance are finding by varying mass flow rate of working fluid. And this experimental investigation on corrugated PHE can be extended with various fluids. This work can be further extended for heat transfer analysis by further process. 
Journal of Manufacturing Engineering, March, 2021, Vol. 16, Issue. 1, pp 007-011

\section{References}

1. Bani Kananeh, E. Scharnbeck, U.D. Kück, N. Räbiger (2010), Reduction of milk fouling inside gasketed plate heat exchanger using nano-coatings food and bioproducts processing (88):349-35

2. Marzia Giribaldi, Alessandra Coscia, Chiara Peila, Sara Antoniazzi, Cristina Lamberti, Marco Ortoffi, (2016), Pasteurization of human milk by a benchtop HighTemperature Short-Time device, Innovative Food Science and Emerging Technologies (36), 228-233

3. Phavanee Narataruksa, Waraporn Pichitvittayakarn, Peter J. Heggs, Suvit Tia (2010), Fouling behavior of coconut milk at pasteurization temperatures Applied Thermal Engineering (30):1387-1395.

4. W. Augustin, T. Geddert and S. Scholl (2007), Surface Treatment for The Mitigation of Whey Protein Fouling, Proceedings of 7 th International Conference on Heat Proceedings of 7 th International Conference on Heat
Exchanger Fouling and Cleaning, Institute for Chemical and Thermal Process Engineering.

5. K. S. Hong, Tae-Keun Hong, and Ho-Soon Yang, (2005), thermal conductivity of Fe nanofluids depending on cluster size of nanoparticles. 